\title{
Verbal inflection errors in child L1
}

\section{Syntax or phonology?}

\author{
Simone Buijs, Sabine van Reijen and Fred Weerman \\ University of Amsterdam
}

Song, Sundara \& Demuth (2009) find an asymmetrical pattern for verbal inflection errors in child English: They observe more errors in sentence medial position than in sentence final position. To account for this asymmetry, they point towards the surface differences of both sentence positions. A similar asymmetry in Dutch, in which embedded clauses cause fewer problems for verbal inflection than main clauses, has been related to V2 (van Kampen 1997; Bastiaanse \& van Zonneveld 1998; Weerman, Duinmeijer \& Orgassa 2011). The present study disentangles both explanations (sentence position, i.e. 'phonology' vs. V2, i.e. 'syntax'), and aims to provide a unified account for both the patterns found in English and Dutch. The inclusion of PP-over-V constructions in a sentence repetition task with monolingual Dutch children (aged 4;0 to 6;2) enables us to show that the phonological account proposed for English can account for the Dutch pattern as well.

Keywords: verbal inflection, phonology, V2, L1 acquisition

\section{Introduction}

Recent work on the acquisition of verbal agreement in Dutch and English supports the claim that children are "little inflection machines" (Wexler 1998:27) in that knowledge of verbal agreement seems to be in place at a very early age. This does not imply, however, that children do not make mistakes at all. Instead, the idea is that these errors may not be due to lack of knowledge of the inflectional (morphological) system, but rather that they may be caused by processing factors. The question is what these factors are.

Song, Sundara \& Demuth (2009), for instance, show that there are sentenceposition effects for English third person singular $-s$ : Children's production of this suffix is more successful in sentence final position, as in (1a), than in sentence medial position (cf. 1b). 


\section{(1) a. There he sleeps \\ b. He sleeps now}

Song et al. argue that utterance medial syllables differ from utterance final syllables for two reasons. For one, they are usually shorter in duration than utterance final syllables; for another, they are always followed by other words. Put differently, the child simply has less time to produce third person singular $-s$ when the inflected verb is in sentence medial position, and therefore makes more inflection errors with constructions of this type. When the inflected verb is in sentence final position, however, the child is left with more time to produce the inflectional morpheme, allowing him to make fewer errors. Hence, while English children may know that a suffix $-s$ is required, their performance will be influenced by a general constraint giving the final position an advantage when it comes to the production of the third person singular suffix. Although the precise character of this constraint is still to be determined, we will refer to it as a 'phonological' constraint since the surface order is assumed to be relevant (but nothing special hinges on this terminology).

On the other hand, Dutch work on acquisition has suggested that a more abstract factor plays a role in inflection errors. In this view, the syntax, that is Verb Second (V2), is a factor that may influence the production of finiteness, since children (or more generally, speakers with processing limitations) might want to prevent V2 ('V-to-C') for processing reasons. This could explain the use of so-called dummies as in (2a) (cf. van Kampen 1997; Zuckerman 2001; Blom \& de Korte 2008 among others). The general idea is that, in order to prevent the finite main verb from having to move, a dummy verb is inserted in second position, allowing the main verb to remain uninflected in sentence final position. If verb movement is indeed an extra processing burden, it may in turn affect verbal inflection of main verbs too. More specifically, we may expect more inflectional errors if V2 takes place. In this way, the processing burden caused by verb movement can account for why speakers make fewer inflectional mistakes when V2 does not take place, as in embedded sentences like (2b), than when it does, as in root clauses such as (2c) (cf. Bastiaanse \& van Zonneveld 1998; Weerman, Duinmeijer \& Orgassa 2011 among others).

(2) a. Papa doe-t een boek lezen

Daddy do-3sg a book read

'Daddy is reading a book.'

b. ...dat papa een boek lees-t

...that Daddy a book read-3sG

'...that Daddy is reading a book.'

c. Papa lees-t een boek

Daddy read-3sg a book

'Daddy is reading a book.' 
This raises the question of how these two possible factors ('advantage of final position', i.e. phonology, and 'advantage of avoidance of verb movement', i.e. syntax) relate to each other. More particularly, the question is whether we can account for both the English and the Dutch facts in the same way. Since English does not exhibit V2, the most straightforward way to find an explanation is to investigate whether a phonological explanation is plausible for Dutch as well. However, Dutch sentences like $(2 \mathrm{~b}-\mathrm{c})$ do not allow us to decide on this issue, since we cannot disentangle the two factors in these kind of sentences. Here, both approaches make exactly the same prediction: Inflection in (2b) could be better either for a phonological reason (the verb is in sentence final position) or a syntactic reason (there is no V2). In fact, the two approaches could even be correct at the same time.

Fortunately, not all Dutch sentences are ambiguous in this respect. In the present study, we will therefore look at verbal inflection within the so-called PPover-V construction (cf. Koster 1974; Neeleman \& Weerman 1999 among others) in which V-PP orders are derived without moving the verb to the second position. This can be illustrated with the sentences in (3). The sentences (3a-b) are similar to $(2 b-c)$, except for the fact that the complement of the verb is not a DP but a PP. Crucially, the PP can optionally appear to the right of a verb in an embedded clause, as (3c) shows.

(3) a. ... dat Piet over zijn vader droom- $t$

that Pete about his father dream-3sG

'...that Pete is dreaming about his father.'

b. Piet droom- $t$ over zijn vader

Pete dream-3sg about his father

'Pete is dreaming about his father.'

c. ... dat Piet droom-t over zijn vader

that Pete dream-3sg about his father

'... that Pete is dreaming about his father.'

There is some discussion about the precise analysis of V2, but in generative approaches it is generally accepted that the verb is moved to the left in root sentences like (2c) and (3b). There is also some discussion regarding the analysis of Dutch PP-over-V. Koster (1974), for instance, suggests that the PP is moved to the right, whereas Neeleman \& Weerman (1999) propose that it can be base-generated in the position on the right-hand side of the verb. Crucially, however, scholars do agree that the verb in sentences like (3c) is not moved to the V2 position. Thus, since the verb in (3c) is neither in final nor in V2 position, the paradigm in (3) allows us to disentangle the phonological and the syntactic explanation, at least in principle. On the one hand, the syntactic account predicts that the child will not encounter verbal inflection difficulties in sentences like (3c), as the verb is not 
moved to V2 position. On the other hand, the phonological account predicts that the child will encounter difficulties in such sentences, as the inflected verb is in sentence medial position. In the present study, we therefore take a closer look at verbal inflection errors in monolingual Dutch children, taking into account sentences with PP-over-V alongside sentences as $(3 \mathrm{a}-\mathrm{b})$. How we operationalize this is discussed in Section 2. In Sections 3 and 4 we present the results and some concluding remarks, respectively.

\section{Method}

The present study takes a look at verbal inflection errors in child Dutch in order to provide a unified account for patterns found in both English and Dutch. We use sentences with PP-over-V constructions (henceforth V-PP) to disentangle syntactic and phonological factors affecting verbal inflection. Of course, an experiment focusing on such V-PP orders alone is incomplete. Therefore, sentences with V2 and with the finite verb in final position (PP-V) are included in the study in order to make the appropriate comparisons. The constructions included in the experiment are presented in Table 1 (see example (3) for glosses).

Table 1. Construction types and their properties

\begin{tabular}{llll}
\hline $\begin{array}{l}\text { Construction } \\
\text { type }\end{array}$ & Example & $\begin{array}{l}\text { Final } \\
\text { position }\end{array}$ & V2 \\
\hline PP-V & $\begin{array}{l}\text { Jan zegt dat Piet over zijn vader droomt. } \\
\text { John says that Pete about his father dreams. }\end{array}$ & + & - \\
V-PP & Jan zegt dat Piet droomt over zijn vader. & - & - \\
& John says that Pete dreams about his father. & & + \\
V2 & Jan zegt: Piet droomt over zijn vader. & - & + \\
\hline
\end{tabular}

If only V2 plays a role in the problems regarding inflection, the production of third person singular $-t$ in PP-V and V-PP sentences should be better than in V2 sentences. If only the final position plays a role, PP-V sentences should yield better production results than V-PP and V2 sentences. If both factors are relevant, children should perform better on PP-V sentences than on V-PP ones, and better on V-PP sentences than on V2 sentences.

The different construction types were tested by means of a sentence repetition task. The basic idea behind such a task is that the child is not able to repeat the sentences in the task using his memory alone, and thus is forced to use his own linguistic capacities to recreate the sentence (Eisenbeiss 2010). In total, 12 verbs were used, which were chosen based on production data from Dutch corpora in 
the CHILDES database (MacWhinney 2000; van Kampen 1994; Wijnen \& Verrips 1998): All verbs included in the task were found in CHILDES to be uttered by children younger than those tested here. This helped to ensure that all verbs and all constructions used in the experiment were known to the children. As the complexity of the consonant cluster at the end of a verb stem could influence the production of the third person singular ending (cf. Song et al. 2009), we made sure that the stems of the verbs used for the present study ended with only one consonant, leading to a cluster consisting of a consonant and the 3SG suffix $-t$ for each verb. In (4), all verbs used in the present study are listed. In case the verb is followed by a PP, we ensured that the preposition starts with a vowel in order to prevent more complex consonant clusters.
(4) Bellen ('to call')
Lachen ('to laugh')
Slapen ('to sleep')
Dromen ('to dream') Lezen ('to read')
Spelen ('to play')
Geven ('to give')
Peuteren ('to pick')
Vertellen ('to tell')
Knippen ('to cut')
Plassen ('to pee')
Zwemmen ('to swim')

To avoid memory effects, all test items needed to have the same length. In line with previous studies on sentence repetition tasks with children of four to six years old (e.g. Montgomery, Montgomery \& Stephens 1978), all sentences in the present study contained nine words. An example of a set of construction types used is given in (5) for the verb zwemmen ('to swim').

(5) a. Jan zeg- $t$ dat kleine Tim in zijn badje $z w e m-t$

PP-V

John say-3sg that little Tim in his bath swim-3sg

'John says that little Tim swims in his bath.'

b. Jan zeg- $t$ dat kleine Tim zwem- $t$ in zijn badje

John say-3sg that little Tim swim-3sg in his bath

'John says that little Tim swims in his bath.'

c. Jan zeg- $t$ nu: Kleine Tim zwem- $t$ in zijn badje

John say-3sg now: Little Tim swim-3sg in his bath 'John says that little Tim swims in his bath.'

Each child was presented with all three construction types of either eight or four verbs, depending on whether the child participated in the present study or in its collaborative study on verb raising (Meyer 2012). The items of the present study were used as fillers in that study (and vice versa). The verb raising study aimed to find verb order preferences of both bipartite and tripartite verb clusters. In the bipartite sample, four out of twelve verbs from the present study were tested as filler material. In return, all of the tripartite clusters were sampled throughout the present study. Both studies had a test item:filler item ratio of 2:1. An example of 
both a bipartite and a tripartite test item from the verb cluster study is given in respectively (6a) and (6b).

(6) a. Joost denk-t dat Piet heel erg hard kan lachen Joost think-3sg that Pete really really loudly can.sg laugh 'Joost thinks that Pete can laugh very loudly.'

b. Loes denk-t dat de beer taart gegeten moet hebben Loes think-3sg that the bear cake eaten must have 'Loes thinks that the bear must have eaten cake.'

Obviously, the verb cluster items had to meet the same criteria as the items from the present study.

If we were to offer only grammatical sentences, this could lead to biased results since children may remember the last word of a sentence more easily. In that case, children might use the correctly inflected verb in final position more frequently only because they have just heard it. In order to prevent this bias, the test items were offered in both a grammatical and an ungrammatical condition, following Keeney \& Wolfe (1972). Half of the verbs presented to the child contained the third person singular ending $-t$ (the grammatical condition), while the other half of the verbs did not contain the ending and were bare (the ungrammatical condition).

All test sentences were recorded by the same female speaker using neutral intonation and stress. This way, we could ensure that all children were presented the sentences in exactly the same way and that possible intonational differences did not influence the results.

In total, 49 monolingual Dutch children participated in this experiment: 22 boys and 27 girls. The mean age of the group at the moment of testing was 4;9, with ages ranging from 4;0-6;2. All children attended primary school in the western region of the Netherlands, spoke standard Dutch, and were typically developing. Every child was seen individually in a separate room, accompanied by two experimenters. The child was asked to look at a series of pictures on a computer screen. For each picture, the child listened to a recording of one of the test items and was asked to repeat the sentence as precisely as possible. Before the experiment began, three practice items were presented. If the child had difficulties repeating these items, the experimenters helped and supported the child. The actual experiment began when the child seemed able to repeat the presented sentences.

At the moment of testing, one of the two experimenters noted not only what type of construction was uttered with which verb, but also whether the participant produced a $-t$ ending, or whether he did not. Every produced construction was therefore coded for either 'with $-t$ ' or 'without $-t$ '. All sessions were recorded, and all scores were checked. In the event that there was a difference of opinion, the opinion of a third judge was decisive. 


\section{Results}

The results show that the children did not always reproduce the construction type presented to them. Instead, the children often produced one of the other two construction types, or a completely different construction type irrelevant to the present study. The spread of produced construction types - in both the grammatical and ungrammatical condition taken together - is presented in Table 2. Overall, children were more likely to produce PP-V constructions (subordinate clauses) than V2 constructions (main clauses) or V-PP constructions. The construction types that were coded as 'other' in Table 2 are irrelevant to the present study. These are answers in which the child used a different tense or number, answers in which a dummy-like construction was used, answers in which the child used a completely different verb, or answers in which the verb was left out altogether. The 'other' items will not be taken into account in the analysis.

Table 2. Spread of produced construction types

\begin{tabular}{llrrrrl}
\hline & & \multicolumn{3}{c}{ Produced construction } & \multirow{2}{*}{ Total presented } \\
\cline { 3 - 5 } & & PP-V & V-PP & V2 & Other & \\
\hline \multirow{2}{*}{ Presented } & PP-V & 243 & 5 & 15 & 29 & 292 \\
construction & V-PP & 126 & 90 & 20 & 56 & 292 \\
& V2 & 78 & 16 & 152 & 46 & 292 \\
Total produced & & 447 & 111 & 187 & 131 & 876 \\
\hline
\end{tabular}

A repeated measures ANOVA with construction type as three-level within subjects factor reveals an effect for construction type $(\mathrm{F}(1.639,47)=9.670, \mathrm{p}<$ 0.001). Pairwise comparisons (that are corrected for multiple comparisons using Bonferroni's adjustment) show that the children made significantly fewer inflectional errors in PP-V constructions than in both the V-PP constructions ( $\mathrm{p}<$ $0.001)$ and V2 constructions ( $\mathrm{p}<0.05)$. The difference between V-PP constructions and V2 constructions does not turn out to be significant $(p=0.211)$.

In addition, the results for the grammatical and ungrammatical condition are analyzed separately. Because of the small amount of responses within each condition, it was not possible to conduct an ANOVA on the obtained results. Therefore, Fister's Exact Tests were conducted to analyze both the grammatical and ungrammatical condition separately. First, we discuss the results for the grammatical condition. The spread of the produced items is presented in Table 3. 
Table 3. Spread of -t/t endings - grammatical condition

\begin{tabular}{lccrc}
\hline & \multicolumn{2}{l}{ Construction type } & Total \\
\cline { 2 - 4 } & PP-V & V-PP & V2 & \\
\hline With $-t$ & 234 & 49 & 83 & 366 \\
Without $-t$ & 4 & 2 & 6 & 12 \\
Total & 238 & 51 & 89 & \\
\hline
\end{tabular}

Table 3 shows the number of $-t$ deletions for each construction type within the grammatical condition. There are clearly not many mistakes, which supports the view that Dutch children in general do not have problems with verbal inflection at this age. A first Fisher's Exact Test comparing the difference between the PP-V construction on the one hand and the V-PP construction on the other hand shows that this difference is not significant $(p=0.286)$. A second follow-up Fisher's Exact Test reveals that the difference between the PP-V construction and the V2 cases is significant $(\mathrm{p}<0.05)$, and a final Fisher's Exact Test shows that the difference between the V-PP construction and the V2 construction is again not significant $(\mathrm{p}=0.710)$.

The results for the grammatical condition thus reveal a significant difference between the PP-V construction on the one hand and the V2 construction on the other hand. This is the same difference attested in previous studies between the main and subordinate clauses. The newly added V-PP construction does not - at this point - add anything new to the picture. However, the asymmetry attested in previous studies is confirmed by these results.

The results for the ungrammatical condition are presented in Table 4. Note that the 'without $-t$ ' answers are - just like in the grammatical condition - scored as errors here. As mentioned above in the method section, it has been assumed that children will not be able to repeat the sentence purely from memory. Therefore, the child has to reproduce the sentence and it is considered an error when he leaves out the $-t$ ending.

Table 4. Spread of $-t / t$ endings - ungrammatical condition

\begin{tabular}{llllr}
\hline & \multicolumn{2}{l}{ Construction type } & Total \\
\cline { 2 - 4 } & PP-V & V-PP & V2 & \\
\hline With $-t$ & 185 & 46 & 77 & 308 \\
Without $-t$ & 24 & 14 & 21 & 59 \\
Total & 209 & 60 & 98 & \\
\hline
\end{tabular}

The first Fisher's Exact Test shows that the difference between the PP-V construction and the V-PP construction is significant $(\mathrm{p}<0.05)$. The second Fisher's Exact Test shows that the difference between the PP-V construction and the V2 
construction is also significant $(\mathrm{p}<0.05)$. The final Fisher's Exact Test comparing the V-PP construction and the V2 construction does not indicate a significant difference $(\mathrm{p}=0.844)$.

Thus, like the grammatical condition, the results for the ungrammatical condition show a significant difference between V2 constructions (main clauses) on the one hand and PP-V constructions (embedded clauses) on the other hand. In addition, the ungrammatical condition shows a significant difference between the $\mathrm{PP}-\mathrm{V}$ construction and the V-PP construction. The difference between the pattern found for the grammatical condition and the ungrammatical condition might be explained by the fact that children make very few errors in the grammatical condition, leaving little to measure within this condition.

In sum, the grammatical and the ungrammatical condition together show that children score significantly better on the PP-V constructions, as compared to both the V-PP and the V2 construction types. On its own, the grammatical condition does not show a significant difference between the (small) number of deleted $-t$ endings in the V-PP construction and the number of deleted $-t$ endings in either of the two other construction types. Within the ungrammatical condition however, the V-PP construction does show a significant difference, but only with the PP-V construction and not with the V2 construction. In other words, in the ungrammatical condition, children made significantly more errors when the verb was in sentence medial position (V-PP and V2 constructions), as compared to those cases where the verb was in sentence final position (PP-V constructions). As noted, this pattern remains intact when the two conditions are analyzed together. Crucially, the fact that the number of absent $-t$ endings within the V-PP construction (no V2) does not differ significantly from the number of absent $-t$ endings within the V2 construction (V2), leads us to conclude that V2 does not play a significant role in the domain of verbal inflection.

\section{Discussion and conclusions}

The present study aimed to find one explanation that can account for the asymmetrical pattern of verbal inflection errors attested in both Dutch and English. In order to do so, we took a closer look at verbal inflection errors in Dutch. We compared not only main and embedded clauses, which have revealed the asymmetry in previous studies, but also included PP-over-V constructions to help us disentangle previously presented explanations.

The results of the present study point towards a phonological account for verbal inflection errors in child Dutch. Although results from the grammatical test items did not provide any new insights, they did confirm the previously attested 
asymmetry. The results from the ungrammatical test items revealed that children make significantly more inflection errors when the inflected verb is in sentence medial position (the V-PP and the V2 constructions) as compared to when the verb is in sentence final position (the PP-V construction). The same pattern emerged when all the items were analyzed together: More inflectional errors are made when the inflected verb is in sentence medial position than when it is in sentence final position. This shows that the phonological constraint that favors sentence final position over sentence medial position does indeed affect verbal inflection. Crucially, the difference between verbal inflection errors in V-PP constructions (no V2) and in V2 constructions (V2) did not turn out to be significant. This reveals that V2 does not play a significant role when it comes to verbal inflection errors. In short, the phonological constraints proposed for verbal inflection in child English, can also account for the patterns attested in child Dutch. Apparently, the production time in sentence medial position is not always sufficient for children to produce the grammatical morpheme $-t$. In contrast, the child has enough time to produce the ending at sentence final position, leading to fewer errors.

In the above, we follow the literature in assuming that notions like sentence final position and/or V2 play a role in the competing explanations. However, one might also be tempted to suggest an alternative interpretation of the data, arguing that PP-over-V in Dutch may also somehow be a factor that leads to an extra processing burden. Crucially, though, even if this were a viable explanation for the Dutch results, notions like V2 and PP-over-V cannot be used to explain the asymmetry in English, since English simply does not have these properties. The advantage of our proposal is that it leads to a unified account of the results in English and Dutch.

Nevertheless, it should be acknowledged that additional experiments are necessary to disentangle further options. For instance, if our analysis is correct, we would expect a Dutch sentence with V2 but with the verb in final position (a sentence without additional complements like hij slaapt 'he sleeps') to be similar to an embedded sentence (...dat hij slaapt 'that he sleeps') with respect to inflection errors. Furthermore, even though the present study did reveal significant results, the overall picture showed that even four-year-old children make very few inflection errors. Future research should therefore focus on verbal inflection errors in children younger than four. Since younger children are expected to make more inflection errors, that age group should be able to provide us with more robust data.

If the processing burden of $\mathrm{V} 2$ does not suffice to explain the asymmetry in inflection errors, we might also want to reconsider the explanation previously given for DO-support in child Dutch. As noted before, the general opinion is that children use empty dummy auxiliaries in order to avoid moving the main verb to the V2 position. However, the results of the present study indicate that as far as verbal 
inflection is concerned, it is not so much V2 that causes problems but rather the resulting middle position. If this observation is valid for verbal inflection, one might wonder if this factor is somehow also responsible for the asymmetry observed in Dutch DO-support. Perhaps children prefer to use frequent and hence relatively stable forms like auxiliaries in the middle position to prevent processing problems.

\section{Acknowledgements}

We would like to thank Caitlin Meyer for all of her support in so many different ways, Sible Andringa for the statistical help and advice, two anonymous reviewers for their comments and all of the schools, parents and children that participated in this study.

\section{References}

Bastiaanse, Roelien \& Ron van Zonneveld. 1998. On the relation between verb inflection and verb position in Dutch agrammatic aphasics. Brain and Language 64. 165-181.

Blom, Elma \& Siebe de Korte. 2008. De verwerving van het Nederlands: Dummies en verb second. Nederlandse Taalkunde 13(2). 133-159.

Eisenbeiss, Sonja. 2010. Production Methods. In Blom, Elma \& Sharon Unsworth (eds.), Experimental methods in language acquisition research, 11-34. Amsterdam/Philadelphia: John Benjamins.

Kampen, Jacqueline van. 1994. The learnability of the left branch condition. In Bok-Bennema, Reineke \& Crit Cremers (eds.), Linguistics in the Netherlands 11, 83-94. Amsterdam/ Philadelphia: John Benjamins.

Kampen, Jacqueline van. 1997. First steps in Wh-movement. Utrecht: Utrecht University/LOT dissertation.

Keeney, Terrence \& Jean Wolfe. 1972. The acquisition of agreement in English. Journal of Verbal Learning and Verbal Behavior 11(6). 698-705.

Koster, Jan. 1974. Het werkwoord als spiegelcentrum. Spektator 3. 601-619.

MacWhinney, Brian. 2000. The CHILDES project: Tools for analyzing talk: Vol. 2. The database. London: Lawrence Erlbaum Associates, Inc.

Meyer, Caitlin M. 2012. Easy as 1-2-(3)? The acquisition of verb cluster orders in Dutch. Amsterdam: University of Amsterdam MA Thesis.

Montgomery, Marcia M., Allen A. Montgomery \& M. Irene Stephens. 1978. Sentence repetition in preschoolers: Effects of length, complexity, and word familiarity. Journal of Psycholinguistic Research 7(6). 435-452.

Neeleman, Ad \& Fred Weerman. 1999. Flexible syntax: A theory of case and arguments. Studies in Natural Language and Linguistic Theory 47. Dordrecht: Kluwer.

Song, Jae Yung, Megha Sundara \& Katherine Demuth. 2009. Phonological constraints on children's production of English 3rd person singular -s. Journal of Speech, Language and Hearing Research 52(3). 623-642. 
Weerman, Fred, Iris Duinmeijer \& Antje Orgassa. 2011. Effecten van SLI op Nederlandse congruentie. Nederlandse Taalkunde 16(1). 30-55.

Wexler, Kenneth. 1998. Very early parameter setting and the unique checking constraint: a new explanation of the optional infinitive stage. Lingua 106(1/4). 23-79.

Wijnen, Frank \& Maaike Verrips. 1998. The acquisition of Dutch ayntax. In Gillis, Steven \& Annick de Houwer (eds.), The acquisition of Dutch, 223-300. Amsterdam/Philadelphia: Benjamins.

Zuckerman, Shalom. 2001. The acquisition of 'optional' movement. Groningen: University of Groningen dissertation.

\section{Authors' addresses}

Simone Buijs

University of Amsterdam

Spuistraat 134

1012 VB Amsterdam, The Netherlands

sjmbuijs@gmail.com

Fred Weerman

University of Amsterdam

Spuistraat 134

1012 VB Amsterdam, The Netherlands

Weerman@uva.nl
Sabine van Reijen

University of Amsterdam

Spuistraat 134

1012 VB Amsterdam, The Netherlands

Sabine.vanReijen@student.uva.nl 